\title{
Atypical Presentations of Acute Infections in Hospitalized Older Adults: The Prevalence, Predictors, and Outcomes
}

\author{
Doha Rasheedy, ${ }^{1}$ MD, Walaa Wessam Aly, ${ }^{1}$ MD Abeer Hassan Mohamed Matter, ${ }^{1}$ MD
}

1 Geriatrics and Gerontology Department, Faculty of Medicine, Ain Shams University, Cairo, Egypt.

\begin{abstract}
Background/ purpose: Atypical presentation of acute infections, is a well-known phenomenon in older people. It is extensively recognized in the literature but lacks sufficient attention in recent clinical research. Reaching a disease specific diagnosis in those with subtle, nonspecific, or atypical presentations is a major challenge. The aim of this study was to report the prevalence of different presentations of acute infections among hospitalized elderly patients, and the factors associated with atypical presentation.
\end{abstract}

Methods: a retrospective medical records review of 220 patients diagnosed with acute infection. The presenting symptoms for each type of infection were reported. Data regarding medical comorbidities, cognition, frailty, and functional status were obtained. Factors associated with the atypical presentation were evaluated.

Results: Urinary tract infections and community-acquired pneumonia accounted for $44.5 \%$ and $25.5 \%$ infections, respectively. The patients presented with atypical symptoms in absence of classical symptoms represented $35.5 \%$ of the cases. $64.5 \%$ of the participants had an absent febrile response. Decreased oral intake was the most prevalent atypical complaint followed by unexplained new-onset functional decline. Dementia and frailty were independent predictors for atypical presentations.

Conclusions: Older adults present acute infections differently. Many common infections present as delirium, new functional decline, new or worsened incontinence [urine, fecal], anorexia, or falls, especially in patients with dementia and frailty. Fever is usually absent in the elderly with acute infections. Moreover, infections in the elderly may present as an exacerbation of chronic stable medical illness e.g. congestive heart failure or diabetes. The inhospital mortality is higher among those having atypical presentations.

Keywords:

Infections in elderly, atypical presentation, pneumonia, Urinary tract infections

\section{Background}

Older adults are at increased risk of infection, which is a leading cause of morbidity and mortality in this age group. ${ }^{[1]}$ The increased infections related mortality in elderly is attributed to multiple factors, including: immunosenescence, medical comorbidities, undernutrition, functional decline, frailty, and increased adverse drug events ${ }^{[2]}$.

Reaching a final disease-specific diagnosis, remains a clinical dilemma when managing older adults. According to Fried et al., less than half of the elderly patients fitted into the classical medical model where the presenting symptoms and signs can refer immediately to a certain disease. ${ }^{[3]}$ In the aged, Infections often have atypical presentations which may complicate and delay diagnosis. The most frequently encountered atypical presentations of infections include delirium, anorexia, functional impairment, falls, fatigue, and new or worsening urinary incontinence. ${ }^{[4,5]}$ Moreover, the classical clinical signs of infectious diseases are usually absent in older patients, causing further diagnostic ambiguity. For instance, many older patients with acute infections have absent febrile response, chills, and leukocytosis. More frequently, infections in elderly manifest as an exacerbation of chronic stable medical illness .e.g. congestive heart failure or diabetes ${ }^{[4]}$.

Thus, health care professionals should remain alert to these atypical and subtle presentations and their associated risk factors to improve clinical outcomes when managing acute infections in elderly.

This study aimed to achieve a better understanding of the prevalence of different presenting features of the 
most common infections among hospitalized medical elderly patients and to detect factors associated with the altered presentations.

\section{Methods}

The medical records of all patients with a definite diagnosis of acute community-acquired infections due to a proven focus of infection admitted to the geriatric medical ward in Ain Shams University hospital, Cairo, Egypt, between March 2017 and February 2019 were reviewed to construct a retrospective observational study.

We excluded cases referred from nursing homes. Those with nosocomial infections, asymptomatic bacteriuria, those presented with severe infections and/ or hemodynamic instability mandating critical care unit admission, cases with surgical infections, or sepsis of unrecognized source when clinical and microbiological data failed to locate any infectious focus were excluded. We excluded cases whose atypical presentations were attributed to causes other than infections like myocardial infarction, any organ failure, new medications, drug withdrawal, fecal impaction, urine retention, etc.

The following data were extracted from patients' medical records:

Age, gender, medical comorbidities, diagnoses, symptoms and signs, cognitive state [Mini mental state examination $[\mathrm{MMSE}]^{[6]}$, clinical frailty scale where degrees of 5 and above denote frailty ${ }^{[7]}$, functional status [activities of daily living [ADL] ${ }^{[8]}$ and instrumental activities of daily living [IADL] [9], laboratory investigations [total leucocyte count, albumin, blood urea nitrogen, creatinine, C-reactive protein [CRP], Chest X-ray, and bacteriological tests [sputum, urine, blood cultures, and other site cultures as required for each case]. In-hospital mortality was also recorded.

Although, diagnosing acute infections in elderly is challenging due to altered presentations and underreporting, an accurate and detailed history and physical examination supported by invasive tests can lead to a correct diagnosis in most of the cases ${ }^{[10]}$. Thus all cases presented with classical localizing symptoms were diagnosed according to clinical guidelines applied per hospital protocol. Any case admitted with any subtle changes or any of the symptoms suggesting atypical presentation were subjected to a systematic diagnostic approach including history, physical examination, laboratory testing (full blood count, liver and kidney functions, electrolytes, and cardiac enzymes), radiological (Chest $\mathrm{X}$ ray, pelviabdominal ultrasound, CT brain), electrocardiogram and bacteriological testing.

\section{Definitions:}

Classical presentations for common infections: included fever, chills, localizing pain, and other localizing symptoms that differed according to the type of infection.

Atypical symptoms: the presence of an unusual symptoms or signs that included delirium, functional impairment, anorexia, incontinence, and falls. ${ }^{[5]}$

\section{Diagnostic criteria for reported infections:}

- Urinary tract infection [UTI] was diagnosed with the presence of urinary symptoms, pyuria, and the isolation of a urinary pathogen in a urine culture. Urinary symptoms include any of the following: dysuria, frequency, urgency, nocturia, hematuria, and suprapubic, loin pain]. Pyuria is the presence of leucocytes $\geq 10 / \mathrm{mm} 3$ in a non-centrifuged urine or $\geq 5 /$ high power field in a centrifuged urine ${ }^{[11]}$

- Diagnosis of community-acquired pneumonia [CAP] was based on: the presence of chest $\mathrm{x}$ ray infiltrates on admission and one or more of symptoms and signs suggesting pneumonia e.g. cough, pleuritic chest pain, dyspnea, expectoration, rigor or night sweating]. Signs suggesting pneumonia include: tachypnea, temperature $>38{ }^{\circ} \mathrm{C}$ or $<35^{\circ} \mathrm{C}$, decreased air entry, limited chest expansion, dullness on percussion, bronchial breathing, and crackles. ${ }^{[12]}$

- Acute exacerbation of chronic obstructive pulmonary disease [AECOPD]: Major symptoms include worsening dyspnea, increased sputum volume and/or purulence, while minor symptoms include increased wheezing, worsened cough, fever, or a $20 \%$ increased breath rate or pulse. ${ }^{[13]}$

- Uncomplicated acute bronchitis: was diagnosed upon clinical presentation, it has no reliable specific signs or laboratory tests. It was diagnosed by the presence of acute cough which can be productive for less than three weeks with or without fever, wheezing, or exertional dyspnea. ${ }^{[14]}$

- Infectious acute gastroenteritis was diagnosed by diarrhea ( $\geq 3$ unformed stools daily) associated with one of the following symptoms [nausea, vomiting, abdominal pain, moderate flatulence, tenesmus, fecal urgency] with or without fever for less than 14 days. ${ }^{[15]}$

- Skin and soft tissue infections [SSTI] are diagnosed by the presence of swelling, localized pain, redness, warmth, ulceration, bullae, and /or oozing discharge. ${ }^{[16]}$

- Infective endocarditis was diagnosed according to the modified Duke criteria. ${ }^{[17]}$

- Acute encephalitis was diagnosed by acute altered mental status, focal neurological signs, seizures, headache, or fever. Diagnosis was 
confirmed by magnetic resonance imaging and lumbar puncture. ${ }^{[18]}$

- Septic arthritis diagnosed by localized joint pain, warmth, limited movement that was confirmed by synovial fluid white cell count $>$ $25,000 / \mathrm{mm} 3$, and synovial fluid aspirate culture. ${ }^{[19]}$

\section{Ethical consideration:}

Data were obtained by retrospective review of medical records after the study methodology was reviewed and approved by the Research Review Board of the Geriatric medicine department, Faculty of Medicine,. Informed consent of participants was not required due to the retrospective study design, moreover, confidentiality and anonymity of all participants were ensured.

\section{Statistical methods:}

The extracted data were coded, tabulated, and analyzed using SPSS package 22. Quantitative variables were presented in the form of means and standard deviation or median and interquartile range as indicated. Qualitative variables were presented in the form of frequency tables [number and percent].

A comparison between quantitative variables was performed using Student t test or Mann-Whitney U. The comparison between qualitative variables was carried out using Pearson's $\chi 2$ test. Logistic regression model was performed to test the significant predictors for atypical presentation. Statistical difference was accepted when $\mathrm{p}<0.05$.

\section{Results}

The study included a total of 220 patients, females comprised $50.1 \%$ of the participants. The mean age of the study participants was $71.82 \pm 7.82$ years old. $78[35.5 \%]$ of the patients presented with atypical nonspecific manifestations in absence of classical ones.

In this study, UTI accounted for $44.5 \%$ of all infections, followed by community-acquired pneumonia [25.5\%], and uncomplicated acute bronchitis accounting for $23.6 \%$ of cases. $25.9 \%$ of cases had more than one focus of infection recorded in their records [Table 1].

About two-thirds of the cases had an absent febrile response to their infection. The decreased oral intake was the most prevalent presenting complaint followed by unexplained new functional decline. Tachypnea and tachycardia were reported in $55.5 \%$ and $40.5 \%$ of cases, respectively [Table 1].

Table 2 showed the prevalence of different presentations for common infections in the studied sample
Table 1: Clinical characteristics of the participants:

\begin{tabular}{|c|c|c|}
\hline \multicolumn{3}{|l|}{ Variables } \\
\hline age & & $71.82 \pm 7.82$ \\
\hline \multirow[t]{2}{*}{ Gender } & male & $90(40.9 \%)$ \\
\hline & female & $130(50.1 \%)$ \\
\hline \multicolumn{3}{|l|}{ Comorbid conditions } \\
\hline \multicolumn{2}{|l|}{ DM } & $101(45.9 \%)$ \\
\hline \multicolumn{2}{|l|}{ HTN } & $125(56.8 \%)$ \\
\hline \multicolumn{2}{|l|}{ Cardiac diseases } & $103(46.8 \%)$ \\
\hline \multicolumn{2}{|l|}{ Pulmonary diseases } & $42(19.1 \%)$ \\
\hline \multicolumn{2}{|l|}{ Cerebrovascular stroke } & $51(23.2 \%)$ \\
\hline \multicolumn{2}{|l|}{ CKD } & $57(25.9 \%)$ \\
\hline \multicolumn{2}{|l|}{ CLD } & $24(10.9 \%)$ \\
\hline \multicolumn{2}{|l|}{ Malignancy } & $2(0.9 \%)$ \\
\hline \multicolumn{2}{|l|}{ Dementia } & $58(26.4 \%)$ \\
\hline \multirow{3}{*}{$\begin{array}{l}\text { Frailty according to } \\
\text { clinical frailty scale(CFS) }\end{array}$} & Robust: CFS(1-3) & $77(35 \%)$ \\
\hline & Prefrail: CFS (4) & $41(18.6 \%)$ \\
\hline & Frail: CFS (5-9) & $102(46.4 \%)$ \\
\hline \multirow{4}{*}{$\begin{array}{l}\text { Baseline functional } \\
\text { status }\end{array}$} & independent & $62(28.2 \%)$ \\
\hline & IADL dependency & $20(9.1 \%)$ \\
\hline & ADL dependency & $52(23.6 \%)$ \\
\hline & Mobility restriction & $86(39.1 \%)$ \\
\hline \multirow{3}{*}{$\begin{array}{l}\text { Number of infections } \\
\text { recorded in each } \\
\text { patient's chart } \\
\text { Source of infection }\end{array}$} & Single site infection & $163(74.1 \%)$ \\
\hline & $\begin{array}{l}\text { Two or more foci of } \\
\text { infection }\end{array}$ & $57(25.9 \%)$ \\
\hline & & \\
\hline \multicolumn{2}{|l|}{ Urinary tract infections } & $98(44.5 \%)$ \\
\hline \multicolumn{2}{|c|}{ community acquired Pneumonia (CAP) } & $56(25.5 \%)$ \\
\hline \multicolumn{2}{|c|}{ skin and soft tissue infections ( SSTIs) } & $44(20.0 \%)$ \\
\hline \multicolumn{2}{|c|}{ Uncomplicated acute bronchitis } & $52(23.6 \%)$ \\
\hline \multicolumn{2}{|c|}{ Acute exacerbation of COPD } & $11(5.0 \%)$ \\
\hline \multicolumn{2}{|c|}{ Infectious acute gastroenteritis } & $10(4.6 \%)$ \\
\hline \multicolumn{2}{|c|}{ Other infections } & $5(2.3 \%)$ \\
\hline \multirow[t]{2}{*}{ Presentation } & assical presentation & $142(64.5 \%)$ \\
\hline & typical presentation & $78(35.5 \%)$ \\
\hline Atypical presentations & & \\
\hline Blunt fever response & & $142(64.5 \%)$ \\
\hline Delirium & & $73(33.2 \%)$ \\
\hline Decreased oral intake & & $80(36.4 \%)$ \\
\hline Recent falls & & $10(4.5 \%)$ \\
\hline New functional decline & & $67(30.5 \%)$ \\
\hline Worsening of chronic me & cal condition & \\
\hline hyperglycemia & & $49(22.4 \%)$ \\
\hline Decompensated Congesti & e heart failure & $38(17.3 \%)$ \\
\hline Decompensated Cor pulm & onale & $15(6.8 \%)$ \\
\hline Fulminant liver cell failure & & $3(1.4 \%)$ \\
\hline Rapid AF & & $9(4.1 \%)$ \\
\hline Other relevant signs & & \\
\hline Tachypnea >20 B/m & & $122(55.5 \%)$ \\
\hline Tachycardia $>90$ bpm & & $89(40.5 \%)$ \\
\hline leukocytosis & & $69(31.4 \%)$ \\
\hline leukopenia & & $3(1.4 \%)$ \\
\hline
\end{tabular}

- $\quad$ SSTIs includes cellulitis 31(14.1\%), infected pressure ulcers 11(5.0\%), diabetic foot $1(0.5 \%)$ and necrotizing Fasciitis $1(0.5 \%)$

- Acute bronchitis 52(23.6\%) of which 25 cases have acute bronchitis without any other sources of infection

- Other infections include a case of spontaneous bacterial peritonitis, one case of septic arthritis, one case of sub-acute infective endocarditis, and two cases of viral encephalitis.

- $\quad$ AF: atrial fibrillation, CKD: chronic kidney disease, CLD: chronic liver disease, COPD: chronic obstructive pulmonary disease, DM: Diabetes Mellitus, HTN: hypertension 
Table 2: Presenting features of each infection:

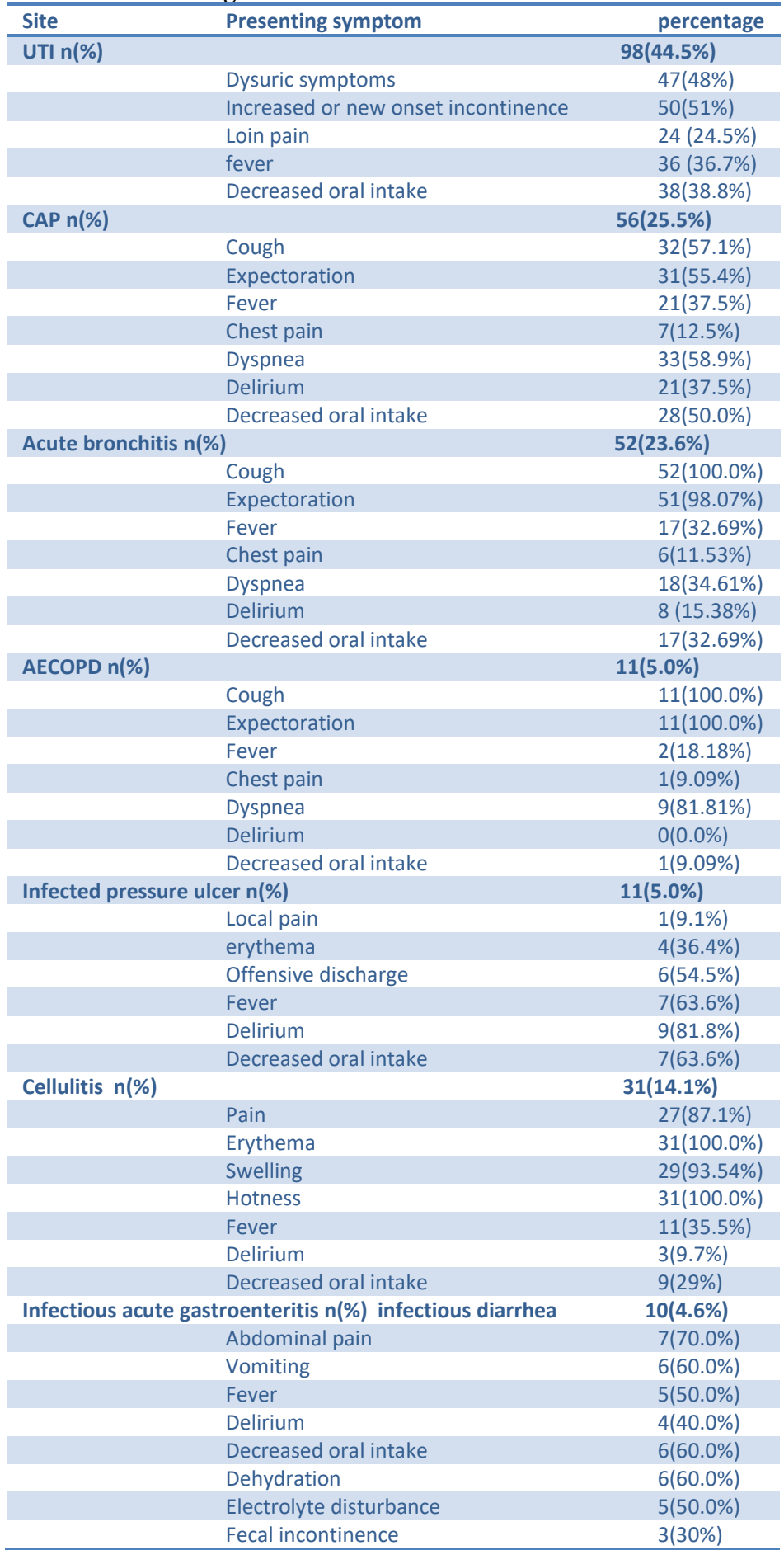

- $\quad$ AECOPD: acute exacerbation of COPD

- $\quad$ CAP: community acquired pneumonia, UTI: urinary tract infections
Comparing patients with classical presentations to those with atypical presentations, revealed that those with atypical presentations were older, had less medical comorbidities, had lower albumin level, and higher CRP levels. Dementia, frailty, and ADL dependency were significantly associated with atypical presentation [Table 3].

Although mortality in our study did not exceed 5\%, it was significantly higher in those with atypical presentation. The mortality included two cases presented with acute confusion [one diagnosed with infected pressure ulcer and the other case had combined UTI and acute bronchitis].

Both cases developed aspiration pneumonia and acute respiratory distress syndrome [ARDS]. Another three cases with CAP deteriorated to respiratory failure and ARDS. One case of infected pressure ulcer developed septic shock and multi-organ failure [MOF]. The case with infective endocarditis developed gentamycin related acute kidney injury requiring repeated dialysis for pulmonary edema. One case of cellulitis was rapidly progressive and was confirmed as necrotizing fasciitis, he was referred to the surgical unit, with postoperative mortality due to septic shock and MOF. One case with viral encephalitis did not respond to acyclovir.

In an adjusted model for age, CRP, albumin, and ADL dependency, the presence of dementia and frailty increased the risk of atypical presentation of infection [Table 4].

Table 3: comparison between those with classical and atypical presentations:

\begin{tabular}{|c|c|c|c|c|}
\hline & & $\begin{array}{l}\text { Cases with } \\
\text { classical } \\
\text { presentation } \\
\mathrm{N}=142\end{array}$ & $\begin{array}{l}\text { Cases } \\
\text { atypically } \\
\text { presented } \\
\mathrm{N}=78\end{array}$ & $P$ value \\
\hline \multicolumn{2}{|l|}{ Age } & $70.99 \pm 7.66$ & $73.33 \pm 7.93$ & $0.034 *$ \\
\hline \multirow[t]{2}{*}{ Gender } & Males & $57(40.1 \%)$ & $33(42.3 \%)$ & \multirow[t]{2}{*}{0.75} \\
\hline & Females & $85(59.9 \%)$ & $45(57.7 \%)$ & \\
\hline \multicolumn{2}{|c|}{$\begin{array}{l}\text { Number of Comorbidities } \\
\text { Median(IQR) }\end{array}$} & $2(2)$ & $2(1)$ & $0.018^{*}$ \\
\hline \multicolumn{2}{|c|}{ Dementia } & $17(12.0 \%)$ & $41(52.60 \%)$ & $<0.0001^{*}$ \\
\hline \multicolumn{2}{|l|}{ Frailty } & $44(31.0 \%)$ & $58(74.4 \%)$ & $<0.0001^{*}$ \\
\hline \multicolumn{2}{|c|}{ ADL dependency } & $74(52.1 \%)$ & $64(82.1 \%)$ & $<0.0001^{*}$ \\
\hline \multicolumn{2}{|l|}{ Albumin } & $3.14 \pm 0.55$ & $2.79 \pm 0.59$ & $<0.0001^{*}$ \\
\hline \multicolumn{2}{|l|}{ CRP ๆ } & $64.71 \pm 55.64$ & $86.98 \pm 64.38$ & $0.014^{*}$ \\
\hline \multicolumn{2}{|c|}{ In hospital mortality } & $2(1.4 \%)$ & $7(9.0 \%)$ & $0.007^{*}$ \\
\hline
\end{tabular}

Table 4: multiple logistic regression for variables associated with atypical presentation for infection in elderly:

\begin{tabular}{|c|c|c|c|c|}
\hline Variable & Coefficient & Odds ratio & $95 \% \mathrm{Cl}$ & $\mathbf{P}$ \\
\hline Age & -0.007 & 0.99 & $0.94-1.04$ & 0.761 \\
\hline Number of comorbidities & -0.719 & 0.48 & $0.33-0.72$ & $0.0003^{*}$ \\
\hline CRP level & 0.006 & 1.01 & $0.99-1.01$ & 0.062 \\
\hline Albumin level & -0.35 & 0.70 & $0.36-1.38$ & 0.304 \\
\hline Frailty & 1.71 & 5.54 & $2.07-14.87$ & $0.0007^{*}$ \\
\hline Dementia & 1.38 & 4.01 & $1.65-9.73$ & $0.002^{*}$ \\
\hline ADL dependency & 0.37 & 1.45 & $0.51-4.07$ & 0.484 \\
\hline Constant & 0.069 & & & 0.974 \\
\hline
\end{tabular}

- $\quad$ *statistical significance, ADL: activity of daily living, CRP: C reactive protein 


\section{Discussion}

This study was conducted to describe the presenting features of acute infections among hospitalized elderly patients in a geriatric medical ward. The inclusion of patients admitted to the geriatric ward while excluding surgical infections and those admitted to the critical care unit had particular advantages that all cases were evaluated by a multidisciplinary geriatric team and underwent comprehensive geriatric assessment.

In the current study, we found that UTI and pneumonia were the most commonly encountered infections. These findings agreed with previous literature ${ }^{[20-22]}$, moreover, we found that UTI was present as a single source of infection in 54 cases [24.5\%], pneumonia was present in 40 cases [18.2\%], and they both co-occurred in 12 patients [5.4\%].

The coexistence of both infections was previously reported by Grabska et al., ${ }^{[23]}$ in $7.5 \%$ of the patients with acute ischemic stroke. Similarly, Ovbiagele et al., ${ }^{[24]}$ reported both infections simultaneously in $2.6 \%$ of the patients with acute stroke. However, both studies analyzed hospitalacquired infections. The exact prevalence of the cooccurrence of both infections in community settings could not be found in the literature.

Absent fever response to infections is common in older adults, especially frail elderly who have lower baseline temperature compared to their healthier counterparts. ${ }^{[25]}$ In this study, 142[64.5\%] of the participants were afebrile. The fever in the elderly is usually defined as a rise in temperature of $\geq 1.3$ o $\mathrm{C}$ above baseline ${ }^{[26]}$. However; it was difficult to obtain the baseline temperature for the studied cohort from their medical records. Thus fever in the current study was defined as temperatures higher than $38^{\circ}$ $\mathrm{C}$ to detect the prevalence of a febrile response using the diagnostic cut off used for young adults.

In the current study, 114 cases presented with exacerbations of their chronic stable condition, 49 of the 101 patients with DM were presented with hyperglycemia [random blood glucose $>200 \mathrm{mg} / \mathrm{dl}$ ]. Hyperglycemia could be a risk factor for immunosuppression causing acute infections or a consequence of the stress caused by acute infections or withholding the usual medications during the acute illness. In the current study, $71.7 \%$ of cases with congestive heart failure presented with acute decompensation. The exact mechanisms of decompensated heart failure during acute infections are not well understood. It could be due to direct infection of the myocardium or myocardial dysfunction caused by circulating or local cytokines. ${ }^{[27]}$ Moreover, it could be attributed to the withholding therapy during acute illness.

Although uncomplicated acute bronchitis is a self-limiting disease caused by viruses in $90 \%$ of cases and does not require antibiotic therapy, 52 cases with uncomplicated acute bronchitis were hospitalized and received antibiotic therapy in our study. 27 of them had another simultaneous source of infection that justified antibiotic use [7 cases had cellulitis, 18 cases had UTI, one case had both UTI and cellulitis, and one case was associated with infectious gastroenteritis]. Another 3 cases presented with delirium that could not be attributed to another cause. However, the remaining 23 cases accounting for $44.23 \%$ of uncomplicated acute bronchitis had unjustified antibiotic use. This was in accordance with many previous studies that reported similar unjustified use of antibiotics for acute bronchitis in the elderly ${ }^{[28]}$ and adults in general. ${ }^{[29]}$

In the current study, the presence of dementia and frailty increased the risk for the atypical presentation in acute infections. Limpawattana et al. reported that baseline dementia was associated with atypical presentations of infections [OR 3.48, 95\% CI 1.38, 8.77, $\mathrm{p}=0.008]^{[5]}$, as those with cognitive impairment may be unable to describe their symptoms.

We have reported that frailty was an independent predictor of atypical presentations, it was not a surprising result. Indeed, the atypical presentation is usually considered a clinical sign of frailty. ${ }^{[30]}$ Frail elderly have decreased reserve, thus their body can't tolerate minor stressors well, leading to deterioration in different organs causing altered presentations.

Regarding mortality, about $4.1 \%$ of the cases included in the current study died during hospital admission. This mortality rate is lower than previously reported data ${ }^{[31,32]}$ because we excluded cases presenting with severe infections and/or hemodynamic instability that mandate critical care unit admission. However, despite this relatively favorable in-hospital mortality, the atypical presentation was significantly associated with higher mortality rates compared to the classical presentation [ $9 \%$ v.s. $1.4 \%, \mathrm{p}=0.007]$, this could be explained by the delayed diagnosis and therefore antibiotic initiation.

This study had several limitations. First, this is a single center study that was performed at the only public standalone geriatric hospital in our country. Second, the study was retrospective limited to routinely collected data, time from presentation till admission was not recorded, post discharge outcome was absent. Third, collecting data of patients admitted to geriatric hospital only, this reduced the inclusion of some infections like infective endocarditis, encephalitis which are commonly admitted to other departments e.g. cardiology and neurology departments.

In conclusion, older adults present acute infections differently. Many common infections present as new functional decline, new or worsened incontinence [urine, fecal], delirium, anorexia, or falls, especially in those with dementia and frailty. Fever is usually absent in the elderly. Moreover, infections in the elderly may present as an exacerbation of chronic stable medical illness e.g. congestive heart failure or diabetes. The in-hospital mortality is higher among those having atypical presentations.

Conflicts of interest: None

Acknowledgement: None 


\section{References}

1. Heppner HJ, Cornel S, Peter W, Philipp B, Katrin S. Infections in the Elderly. Crit Care Clin [Internet] 2013 [cited 2021 Jan 15];29(3):757-74. Available from: https://linkinghub.elsevier.com/retrieve/pii/S0749070413000390

2. Esme M, Topeli A, Yavuz BB, Akova M. Infections in the Elderly Critically-III Patients. Front Med [Internet] 2019 [cited 2021 Jan 15];6:118. Available from: https://www.frontiersin.org/article/10.3389/fmed.2019.00118/full

3. Fried LP, Storer DJ, King DE, Lodder F. Diagnosis of Illness Presentation in the Elderly. J Am Geriatr Soc [Internet] 1991 [cited 2021 Jan 15];39(2):117-23. Available from http://doi.wiley.com/10.1111/j.1532-5415.1991.tb01612.x

4. High KP. Infection: General Principles [Internet]. In: Halter JB, Ouslander JG, Studenski S, High KP, Asthana S, Supiano MA, et al., editors. Hazzard's Geriatric Medicine and Gerontology, 7e. New York, NY: McGraw-Hill Education; 2017 [cited 2020 Oct 5]. Available from: accessmedicine. $\mathrm{mhmedical}$.com/content. aspx?aid=1136599425

5. Limpawattana $P$, Phungoen $P$, Mitsungnern $T$, Laosuangkoon W, Tansangworn N. Atypical presentations of older adults at the emergency department and associated factors. Arch Gerontol Geriatr [Internet] 2016 [cited 2021 Jan 15];62:97-102. Available from: https://linkinghub.elsevier.com/retrieve/pii/S0167494315300480

6. El OkI M, El banouby MH, Mortagy AK, elAtrebi M, ELsabwa M. Prevalence of $A D$ and Other Types of Dementia in Egypt [Internet]. In: International Psychogeriatrics. 2001. page 114.Available from: https://www.cambridge. org/core/journals/internationalpsychogeriatrics/article/abs/oral-sessions/ B1D40249733BD3BA6B02B7E208387A2A

7. Rockwood K. A global clinical measure of fitness and frailty in elderly people. Can Med Assoc J [Internet] 2005 [cited 2021 Jan 15];173(5):489-95. Available

http://www.cmaj.ca/cgi/doi/10.1503/cmaj.050051

8. Katz S, Downs TD, Cash HR, Grotz RC. Progress in Development of the Index of ADL. The Gerontologist [Internet] 1970 [cited 2020 Jan 26];10(1 Part 1):20-30. Available from: https://academic.oup.com/gerontologist/article-

lookup/doi/10.1093/geront/10.1_Part_1.20

9. Lawton MP, Brody EM. Assessment of older people: selfmaintaining and instrumental activities of daily living. The Gerontologist 1969;9(3):179-86.

10. van Duin D. Diagnostic challenges and opportunities in older adults with infectious diseases. Clin Infect Dis Off Publ Infect Dis Soc Am [Internet] 2012;54(7):973-8. Available from: https://pubmed.ncbi.nlm.nih.gov/22186775

11. Scottish Intercollegiate Guidelines Network. Management of suspected bacterial urinary tract infection in adults: a national clinical guideline. Edinburgh: Sign; 2013.

12. Hoare Z, Lim WS. Pneumonia: update on diagnosis and management. BMJ [Internet] 2006;332(7549):1077-9. Available from: https://pubmed.ncbi.nIm.nih.gov/16675815

13. Albertson TE, Louie $\mathrm{S}$, Chan $\mathrm{AL}$. The diagnosis and treatment of elderly patients with acute exacerbation of chronic obstructive pulmonary disease and chronic bronchitis. J Am Geriatr Soc 2010;58(3):570-9.

14. Worrall G. Acute bronchitis. Can Fam Physician Med Fam Can 2008;54(2):238-9.

15. Riddle MS, DuPont HL, Connor BA. ACG Clinical Guideline: Diagnosis, Treatment, and Prevention of Acute Diarrheal Infections in Adults: Am J Gastroenterol [Internet] 2016 [cited 2020 Oct 10];111(5):602-22. Available from: http://journals.Iww.com/00000434201605000-00014

16. Ki V, Rotstein C. Bacterial Skin and Soft Tissue Infections in Adults: A Review of Their Epidemiology, Pathogenesis, Diagnosis Treatment and Site Of Care. Can J Infect Dis Med Microbiol [Internet] 1900;19:846453. Available from: https://doi.org/10.1155/2008/846453 17. Li JS, Sexton DJ, Mick N, Nettles R, Fowler VG, Ryan T, et al. Proposed Modifications to the Duke Criteria for the Diagnosis of Infective Endocarditis. Clin Infect Dis [Internet] 2000 [cited 2021 Jan 15];30(4):633-8. Available from: https://academic.oup.com/cid/article-lookup/doi/10.1086/313753 18. Noska A, Tunkel AR. Central Nervous System Infections in the Elderly. Curr Geriatr Rep [Internet] 2015 [cited 2020 Oct 10];4(1):96104. Available from: http://link.springer.com/10.1007/s13670-014 0110-9

19. Mathews CJ. Septic arthritis in the elderly. Aging Health [Internet] 2010 [cited 2021 Jan 15];6(4):495-500. Available from: https://www.futuremedicine.com/doi/10.2217/ahe.10.43
20. Yahav D, Schlesinger A, Daitch V, Akayzen Y, Farbman L, AbuGhanem $Y$, et al. Presentation of infection in older patients-a prospective study. Ann Med [Internet] 2015 [cited 2021 Jan 15];47(4):354-8. Available from: https://www.tandfonline.com/doi/full/10.3109/07853890.2015.1019915 21. Yoshikawa TT. Epidemiology and Unique Aspects of Aging and Infectious Diseases. Clin Infect Dis [Internet] 2000 [cited 2020 Oct 10];30(6):931-3. Available from: https://academic.oup.com/cid/article-lookup/doi/10.1086/313792

22. Gavazzi G, Krause K-H. Ageing and infection. Lancet Infect Dis [Internet] 2002 [cited 2020 Oct 10];2(11):659-66. Available from: https://linkinghub.elsevier.com/retrieve/pii/S1473309902004371

23. Grabska K, Gromadzka G, Członkowska A. Infections and Ischemic Stroke Outcome. Neurol Res Int [Internet] 2011 [cited 2020 Oct 10];2011:1-8. Available from: https://www.hindawi.com/journals/nri/2011/691348/

24. Ovbiagele B, Hills NK, Saver JL, Johnston SC. Frequency and Determinants of Pneumonia and Urinary Tract Infection During Stroke Hospitalization. J Stroke Cerebrovasc Dis [Internet] 2006 [cited 2020 Oct 10];15(5):209-13. Available from: https://linkinghub.elsevier.com/retrieve/pii/S1052305706000814 25. Norman DC. Fever in the Elderly. Clin Infect Dis [Internet] 2000 [cited 2020 Oct 27];31(1):148-51. Available from: https://doi.org/10.1086/313896

26. Liang SY, Mackowiak PA. Infections in the Elderly. Clin Geriatr Med [Internet] 2007 [cited 2020 Oct 25];23(2):441-56. Available from: https://linkinghub.elsevier.com/retrieve/pii/S0749069007000110

27. Givertz MM, Colucci WS. Chapter 14 - Strategies for Management of Acute Decompensated Heart Failure [Internet]. In: Antman EM, Sabatine MS, editors. Cardiovascular Therapeutics: A Companion to Braunwald's Heart Disease (Fourth Edition). Philadelphia: W.B. Saunders; 2013. page 281-306.Available from: http://www.sciencedirect.com/science/article/pii/B9781455701018000 $14 \mathrm{X}$

28. Gonzales R, Sauaia A, Corbett KK, Maselli JH, Erbacher K, Leeman-castillo BA, et al. Antibiotic Treatment of Acute Respiratory Tract Infections in the Elderly: Effect of a Multidimensional Educational Intervention. J Am Geriatr Soc [Internet] 2004 [cited 2020 Oct 7];52(1):39-45. Available from: https://doi.org/10.1111/j.1532-5415.2004.52008.x

29. Steinman MA, Gonzales R, Linder JA, Landefeld CS. Changing Use of Antibiotics in Community-Based Outpatient Practice, 19911999. Ann Intern Med [Internet] 2003 [cited 2021 Jan 15];138(7):525. Available from: http://annals.org/article.aspx?doi=10.7326/0003-4819-138-7200304010-00008

30. Olde Rikkert M, van lersel MB, van de Pol MHJ, van Asselt D. Atypical Presentation of Disease with Aging [Internet]. In: RollerWirnsberger R, Singler K, Polidori MC, editors. Learning Geriatric Medicine. Cham: Springer International Publishing; 2018 [cited 2021 Jan 15]. page 41-56.Available from: http://link.springer.com/10.1007/978-3-319-61997-2_5 31. Angioni D, Hites M, Jacobs F, De Breucker S. PREDICTIVE FACTORS OF IN-HOSPITAL MORTALITY IN OLDER ADULTS WITH COMMUNITY-ACQUIRED BLOODSTREAM INFECTION. J Frailty Aging 2020;9(4):232-7.

32. Rebelo M, Pereira B, Lima J, Decq-Mota J, Vieira JD, Costa JN. Predictors of in-hospital mortality in elderly patients with bacteraemia admitted to an Internal Medicine ward. Int Arch Med [Internet] 2011 [cited 2020 Oct 25];4(1):33. Available from: http://www.intarchmed.com/content/4/1/33 